\title{
Gender-Related Differences in Chest Pain Syndromes in the Frontiers in CV Medicine Special Issue: Sex \& Gender in CV Medicine
}

OPEN ACCESS

Edited by:

Hester Den Ruijter,

University Medical Center

Utrecht, Netherlands

Reviewed by:

Verena Stangl,

Charité - Universitätsmedizin

Berlin, Germany

Sophie H. Bots,

University Medical Center

Utrecht, Netherlands

*Correspondence:

C. Noel Bairey Merz

noel.baireymerz@cshs.org

†'Present address:

Leslee Shaw,

Blavatnik Family Women's Health Research Institute, Icahn School of Medicine at Mount Sinai, New York,

NY, United States

Specialty section:

This article was submitted to

Sex and Gender in Cardiovascular

Medicine,

a section of the journa

Frontiers in Cardiovascular Medicine

Received: 20 July 2021

Accepted: 13 October 2021

Published: 17 November 2021

Citation:

Mehta PK, Wei J, Shufelt C

Quesada O, Shaw $L$ and Bairey

Merz CN (2021) Gender-Related

Differences in Chest Pain Syndromes

in the Frontiers in CV Medicine Special Issue: Sex \& Gender in CV Medicine.

Front. Cardiovasc. Med. 8:744788.

doi: 10.3389/fcvm.2021.744788

\begin{abstract}
Puja K. Mehta ${ }^{1}$, Janet Wei ${ }^{2}$, Chrisandra Shufelt ${ }^{2}$, Odayme Quesada ${ }^{3}$, Leslee Shaw ${ }^{4 \dagger}$ and C. Noel Bairey Merz ${ }^{2 *}$

${ }^{1}$ Division of Cardiology, Department of Medicine, Emory Clinical Cardiovascular Research Institute and Emory Women's Heart Center, Emory University School of Medicine, Atlanta, GA, United States, ${ }^{2}$ Barbra Streisand Women's Heart Center, Cedars-Sinai Smidt Heart Institute, Los Angeles, CA, United States, ${ }^{3}$ Women's Heart Center, The Christ Hospital Heart Institute, Cincinnati, $\mathrm{OH}$, United States, ${ }^{4}$ Department of Radiology, Weill Cornell Medicine, New York, NY, United States
\end{abstract}

Coronary artery disease (CAD) is the leading cause of morbidity and mortality among both women and men, yet women continue to have delays in diagnosis and treatment. The lack of recognition of sex-specific biological and socio-cultural gender-related differences in chest pain presentation of CAD may, in part, explain these disparities. Sex and gender differences in pain mechanisms including psychological susceptibility, the autonomic nervous system (ANS) reactivity, and visceral innervation likely contribute to chest pain differences. CAD risk scores and typical/atypical angina characterization no longer appear relevant and should not be used in women and men. Women more often have ischemia with no obstructive CAD (INOCA) and myocardial infarction, contributing to diagnostic and therapeutic equipoise. Existing knowledge demonstrates that chest pain often does not relate to obstructive CAD, suggesting a more thoughtful approach to percutaneous coronary intervention $(\mathrm{PCl})$ and medical therapy for chest pain in stable obstructive CAD. Emerging knowledge regarding the central and ANS and visceral pain processing in patients with and without angina offers explanatory mechanisms for chest pain and should be investigated with interdisciplinary teams of cardiologists, neuroscientists, bio-behavioral experts, and pain specialists. Improved understanding of sex and gender differences in chest pain, including biological pathways as well as sociocultural contributions, is needed to improve clinical care in both women and men.

Keywords: sex, gender, chest pain, coronary artery disease, INOCA

\section{INTRODUCTION}

Coronary artery disease (CAD) is the leading cause of morbidity and mortality among both women and men $(1,2)$. However, sex disparities in CAD outcomes persist, as women are more often underdiagnosed or delayed in diagnosis $(3,4)$, receive less guideline-based treatment $(5,6)$, and are not included proportionately in clinical trials (7). Women more often have pre-hospital delay in presentation after chest pain onset (by $\sim 30-45$ min compared to men) $(3,8,9)$. Compared to men, women are underdiagnosed for myocardial infarction, less likely to undergo coronary angiography, and less likely to receive therapies such as revascularization and mechanical circulatory support $(8,10-13)$. 
Excess mortality in women appear to be driven by age, as women are older with more co-morbidities which may contribute to delays in aggressive treatment, and lower preventive therapy compared to men $(4,5)$. In a recently published large meta-analysis of 705,098 patients with STEMI (31\% women), women had higher in-hospital mortality (OR 1.91), repeat myocardial infarction (OR 1.25), stroke (OR 1.67), and major bleeding (OR 1.82) compared to men (8). Furthermore, women more often have no obstructive CAD in the setting of acute coronary syndrome (ACS), NSTEMI, and STEMI (Figure 1), (14) potentially contributing to diagnostic and therapeutic equipoise. Even though standardized STEMI protocols appear to eliminate sex-differences in age-adjusted mortality, contemporary data demonstrate persistent delayed contact-to-reperfusion time, and less guideline-recommended medical therapy in women compared to men (15-17).

\section{SEX AND GENDER DEFINITIONS}

Sex is defined as a person's biological status and is usually categorized as male, female, or intersex. Biological sex is often indicated by the sex chromosomes and the gonads. Sex as a biological variable (SABV) consideration is now an important component of biomedical scientific study rigor (18). Gender is defined as socially constructed characteristics of women and men, and refers to the norms, roles, and relationships of and between groups of women and men. Gender varies from one society to another and can be changed as the socio-cultural attributes of the sex. Sex and gender are different concepts that are often used interchangeably, but within biomedical research sex is biologically defined, and gender remains a social construct relative to the individual and others perception of themselves as a man or a woman, or another gender identity.

\section{CHEST PAIN DEFINITIONS}

Chest pain is defined as discomfort or pain occurring anywhere between the jaw and upper abdomen. Chest pain is a subjective symptom and can have a wide differential, which requires thorough history taking and often additional diagnostic testing. One of the most important etiologies is cardiovascular disease, the leading killer of women and men $(1,19)$. Chest pain often does not correlate with objective measures of myocardial ischemia or obstructive CAD and is influenced by psychological status (20), suggesting an inclusive approach to chest pain symptom etiology. Emerging knowledge of the cardiovascular stress response to psychosocial stressors in patients with cardiac risk factors has recently been reviewed and may provide insight into angina and other cardiovascular outcomes (Figure 2) (21). Accordingly, chest pain can have biological sex contributions as well as socio-culturally determined gender contributions.

\section{SEX/GENDER CONTRIBUTIONS TO CHEST PAIN}

Sex differences in pain perception are well-described, where female sex has higher somatic awareness compared to male sex (22). This potentially leads to women having greater sensitivity but lower specificity for cardiac chest pain. Further, differing phenotypes of biological sex impact pain perception, e.g., younger premenopausal women with relatively high estrogen levels have a greater pain perception compared to older postmenopausal women with lower estrogen levels (23). Younger pre-menopausal women are erroneously thought to be "protected" from CAD, and younger women's pain symptoms are more easily discounted. Specifically, socio-cultural gender is documented to contribute to subjective symptoms, where gender bias in pain diagnosis and treatment has been identified within the patient-provider encounter and treatment decisions (24). A comprehensive evaluation of sex and gender differences in pain includes proximate cause contributions of experiential (abuse, labor, and delivery), psychological (anxiety, depression, post-traumatic stress), genetic (X chromosome imprinting/Y chromosome), neurochemical (adenosine, cytokine expression), organizational (steroid action in development), activational (steroid action in adulthood), systems level (cortical connectivity, vagal nerve modulation), and sociocultural (gender roles, gender role expectations) (25).

\section{SEX/GENDER IN CHEST PAIN AND PSYCHOLOGICAL STATUS}

Comorbid psychological conditions such as anxiety, depression, and post-traumatic stress disorder are highly prevalent in both women and men with CAD, and psychological stress can exacerbate angina (26-29). Depression is associated with chest pain, regardless of CAD severity $(27,30)$, and Pimple et al. have reported that in women, but not in men, chest pain frequency was associated with more mental stress-triggered ischemia detected by nuclear imaging (31). Mental stresstriggered ischemia predicts a 2-fold higher mortality, and abnormal autonomic response to stress leading to increased coronary vascular reactivity is implicated $(32,33)$. We have observed greater peripheral microvascular constriction using peripheral arterial tonometry (PAT) during a mental stress test in women with INOCA compared to matched asymptomatic controls $(34,35)$. A greater number of INOCA subjects had chest pain during mental stress test compared to controls (41 vs. $10 \%, p=0.01)$. Higher anxiety and frustration during mental stress correlated with peripheral vasoconstriction, and compared to asymptomatic controls, those with INOCA remained more anxious, frustrated, and irritated post mental stress testing (35).

\section{SEX/GENDER IN CHEST PAIN AND THE AUTONOMIC NERVOUS SYSTEM}

A relatively large portion of women and men with objective evidence of ischemia or myocardial infarction have coronary microvascular dysfunction (CMD) despite absence of obstructive CAD (36-38). Although more women than men appear to be referred for advanced CMD evaluation, female-specific mechanisms are not well-understood (38-40). Risk factors such as hypertension, diabetes, systemic inflammation, and estrogen deficiency have all been implicated, however these factors do not 


\begin{tabular}{lccr}
\hline \multirow{2}{*}{} & \multicolumn{2}{c}{ No./Total (\%) } & \\
\cline { 2 - 3 } & Women & Men & $P$ Value \\
\hline $\begin{array}{l}\text { Acute coronary syndrome } \\
\text { GUSTO }\end{array}$ & $343 / 1768(19.4)$ & $394 / 4638(8.4)$ & $<.001$ \\
\hline TIMl 18 & $95 / 555(17)$ & $99 / 1091(9)$ & $<.001$ \\
\hline $\begin{array}{l}\text { Unstable angina } \\
\text { TIMI Illa }\end{array}$ & $252 / 826(30.5)$ & $220 / 1580(13.9)$ & $<.001$ \\
\hline MI without ST-segment elevation $^{2}$ & $30 / 113(26.5)$ & $27 / 278(8.3)$ & $<.001$ \\
\hline Ml with ST-segment elevation & $41 / 450(9.1)$ & $55 / 1299(4.2)$ & .001 \\
\hline $\begin{array}{l}\text { Abbreviations: GUSTO, Global Utilization of Streptokinase and t-PA for Occluded Coronary Arteries; MI, myocardial } \\
\text { infarction; TIMI, Thrombosis In Myocardial Infarction. }\end{array}$ & & & \\
\hline
\end{tabular}

FIGURE 1 | Prevalence of "Normal" and non-obstructive coronary arteries in women and men. Normal (no visible angiographic disease) or non-obstructive coronary arteries (luminal irregularities $<50 \%$ ) is found more often in women than men who undergo invasive coronary angiography for acute coronary syndrome and ST-segment elevation myocardial infarction. Reprinted with permission (14).

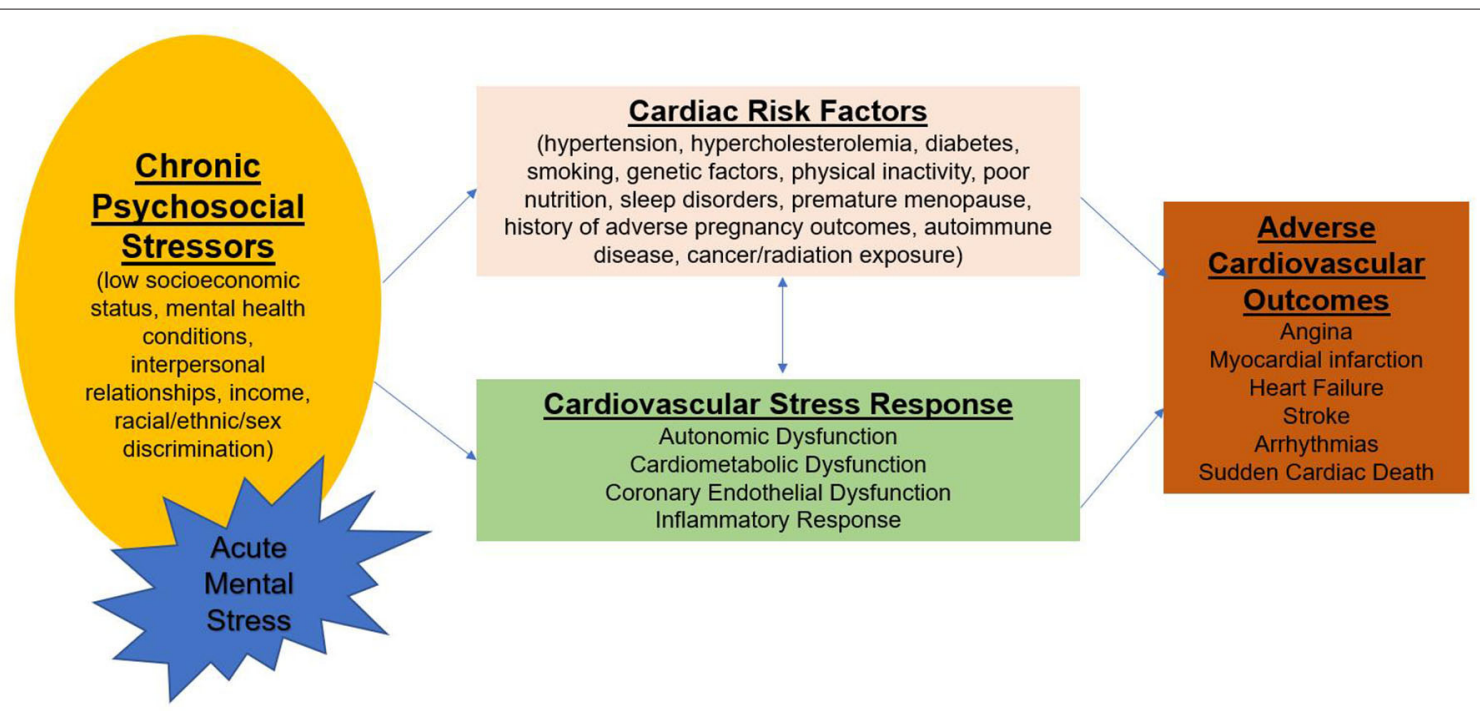

FIGURE 2 | Psychological stress, risk factors, and cardiovascular disease. Acute episodes of mental stress superimposed on chronic stress influence the cardiovascular stress response involving autonomic dysfunction, cardiometabolic dysfunction, endothelial dysfunction, and inflammatory pathways. These pathways are modulated by cardiac risk factors leading to adverse cardiovascular outcomes.

predict CMD-related chest pain (41-43). Failure to auto-regulate myocardial blood flow due impaired microvascular function implicates ANS dysfunction as an important mechanism in CMD-related chest pain syndrome. While increased sympathetic activity due to stimuli such as mental stress may lead to enhanced vasoconstriction, CMD patients are a complex and a heterogeneous group, where a subset appears to have increased cardiac pain sensitivity and high somatic awareness. Prior studies have shown that compared to those with angina from obstructive $\mathrm{CAD}$, patients with no obstructive CAD report more pain with contrast injection in the coronaries, with right ventricle pacing, and with adenosine infusion; furthermore, pain at a lower stimulus intensity is observed in these patients (44-47). However, it is not known whether the exaggerated pain sensitivity is due to abnormal sympathetic activation in the heart vs. abnormal ANS processing of visceral afferent signals $(46,48)$.

\section{SEX/GENDER AND CHEST PAIN AND THE CENTRAL NERVOUS SYSTEM}

The cortico-limbic structures play an important role in emotional regulation, pain processing, and cardiovascular sympathetic 

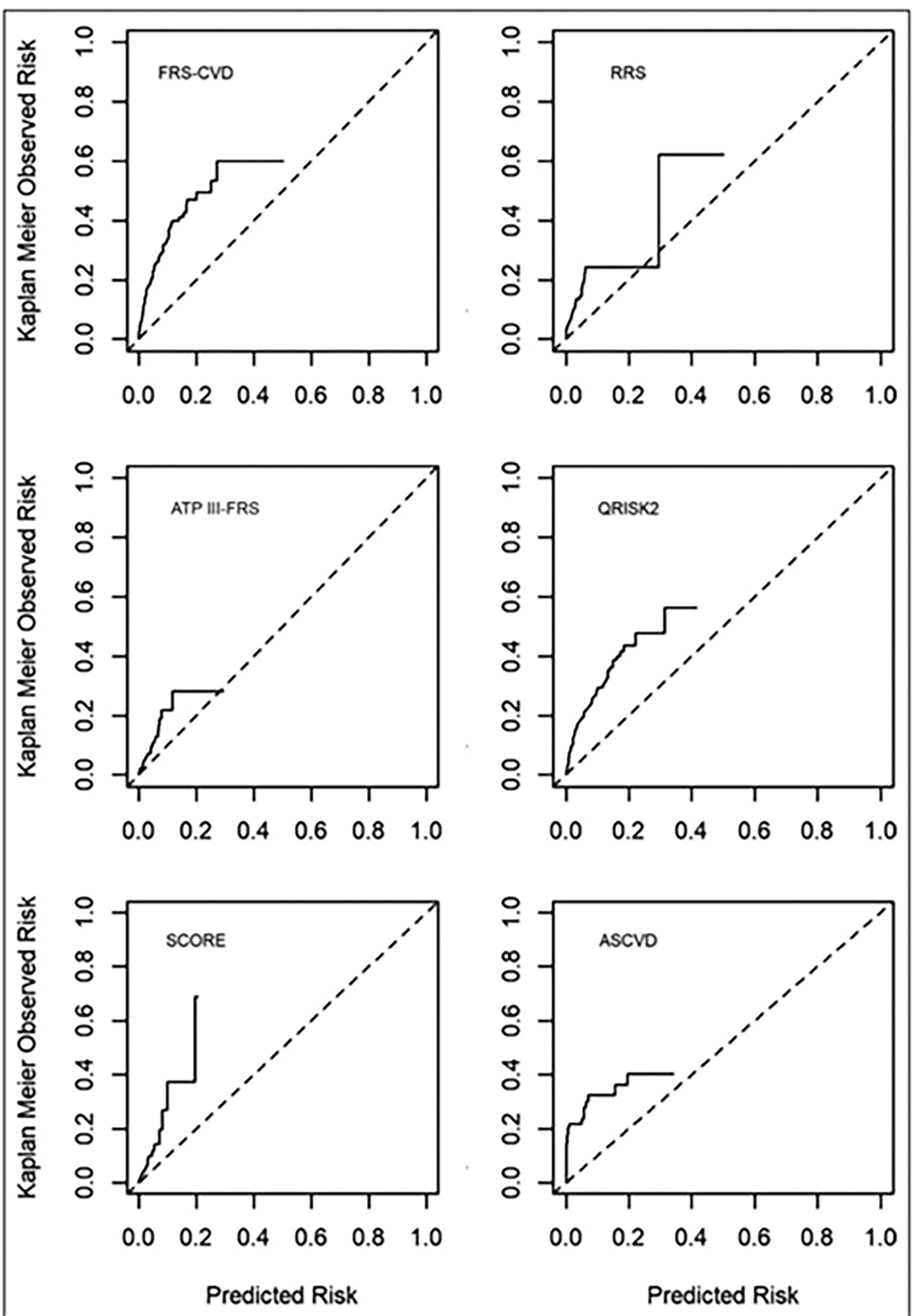

FIGURE 3 | Calibration plots of risk score-specific predicted vs. observed rate of events. Commonly used cardiovascular risk scores significantly underestimate risk in women with ischemia and no obstructive CAD. Dotted line is the reference line for equal predicted and observed risk. Solid line is the observed risk. ASCVD,

Atherosclerotic Cardiovascular Disease risk score; ATP III-FRS, Adult Treatment Panel III risk score; FRS, Framingham Risk Score; QRISK2, cardiovascular risk score; RRS, Reynolds Risk Score; and SCORE, Systematic Coronary Risk Evaluation. Reprinted with permission (66). 


\section{Adjusted CHEST Scores by Race and CAD}
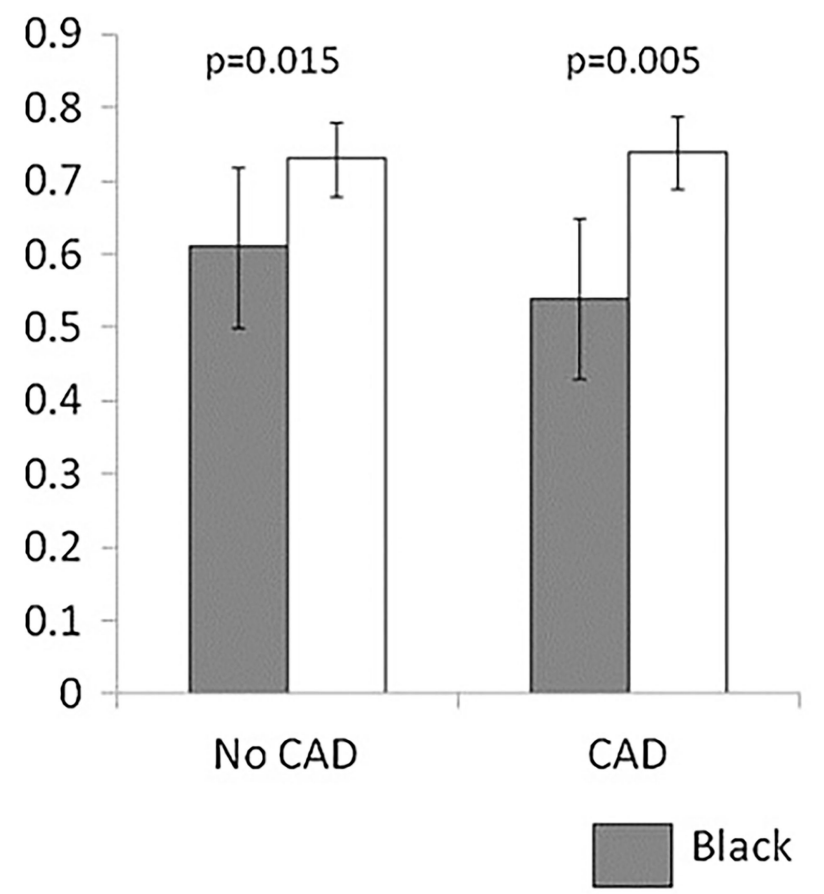

\section{Adjusted STOMACH Scores by Race and $C A D$}

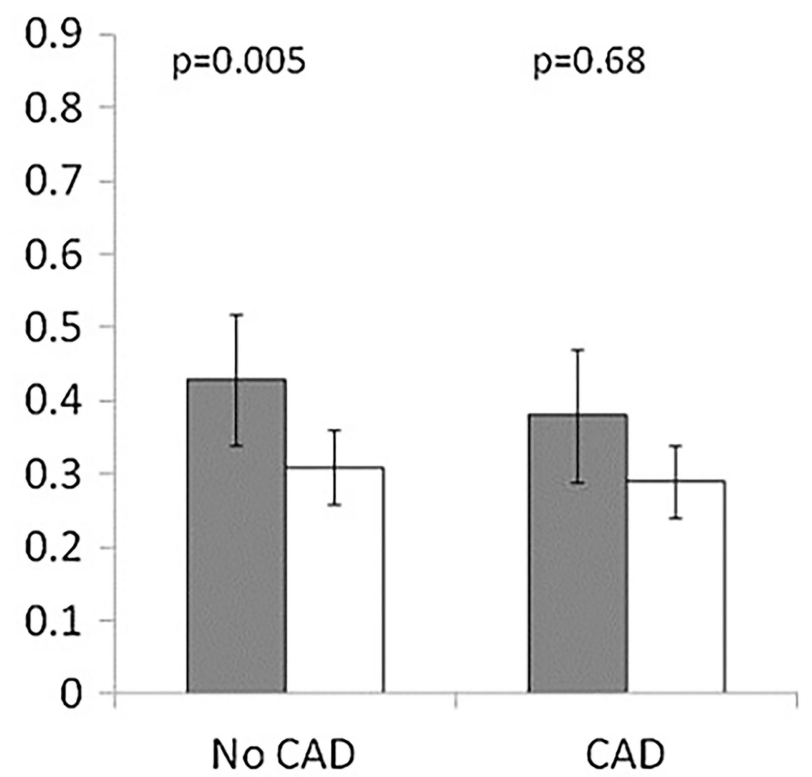

White

FIGURE 4 | Stomach and chest angina symptoms in black women vs. white women with suspected CAD. Symptom clusters were derived from a cohort of 466 women (69 black,397 white) undergoing coronary angiography for suspected CAD. Chest symptoms included chest discomfort, pressure, tightness, fatigue, and shortness of breath. Stomach symptoms included indigestion, esophagus, throat, and abdomen symptoms. Mean adjusted chest and stomach scores stratified by race (black vs. white) and presence vs. absence of obstructive CAD. Reprinted with permission (76).

outflow $(49,50)$. Increased pain sensitivity appears to result from abnormal cortical processing of pain signals. Brain activation was reported in the hypothalamus, periaqueductal gray, thalami, the prefrontal cortex, and the left inferior anterior cingulate cortex (ACC) during chest pain in obstructive CAD patients with ischemia $(51,52)$. Conversely, patients with asymptomatic ischemia did not demonstrate increased frontal cortex activity, although thalamic activation was similar to the chest pain group (51), suggesting that abnormal visceral pain processing of afferent pain signals may be present in mental stresstriggered ischemia. In the Mental Stress Ischemia Prognosis Study (MIPS), CAD patients with angina had increased activation with mental stress in the ACC and associated regions in the inferior frontal gyrus and parietal cortex, compared to those without angina (53). The ACC is a component of the limbic circuit, has extensive connectivity to the insula, amygdala and autonomic centers, and plays a role in processing emotional and fear responses, learning, pain processing, and autonomic cardiovascular responses $(54,55)$. Sex-differences in brain activation patterns during emotional stimuli have been reported, particularly in the amygdala and ACC, with women demonstrating greater activation during negative emotion (56). In particular, heightened amygdalar activity appears to be related to increased risk of Takotsubo syndrome, a condition that is often triggered by emotional or physical stress and predominates in women (57).

\section{SEX/GENDER DIFFERENCES IN CHEST PAIN AND RISK SCORES}

Several chest pain evaluation tools are available for prediction of CAD and adverse events such as myocardial infarction or cardiac death. Both acute and stable suspected CAD presentations differ between women and men $(58,59)$. Specifically, female sex has been shown to influence the entire diagnostic pathway for suspected CAD, from recognizing baseline risk factors to gendered referral to non-invasive testing. Sex and gender differences are well-described in questionnaire tools, including the Rose Questionnaire (60), the Diamond and Forrester tool (61), the updated Diamond-Forrester score (UDF), CAD Consortium clinical score (CAD2), and CONFIRM risk score (CRS), (62) the Duke Clinical Score $(61,63)$. Specifically, these tools developed predominantly in and for men have lower diagnostic accuracy for detection of acute myocardial infarction and stable obstructive $\mathrm{CAD}$ in women, resulting in greater "missed" myocardial infarctions (64), fewer CAD testing referrals (5), less CAD treatment and higher major adverse cardiac event 


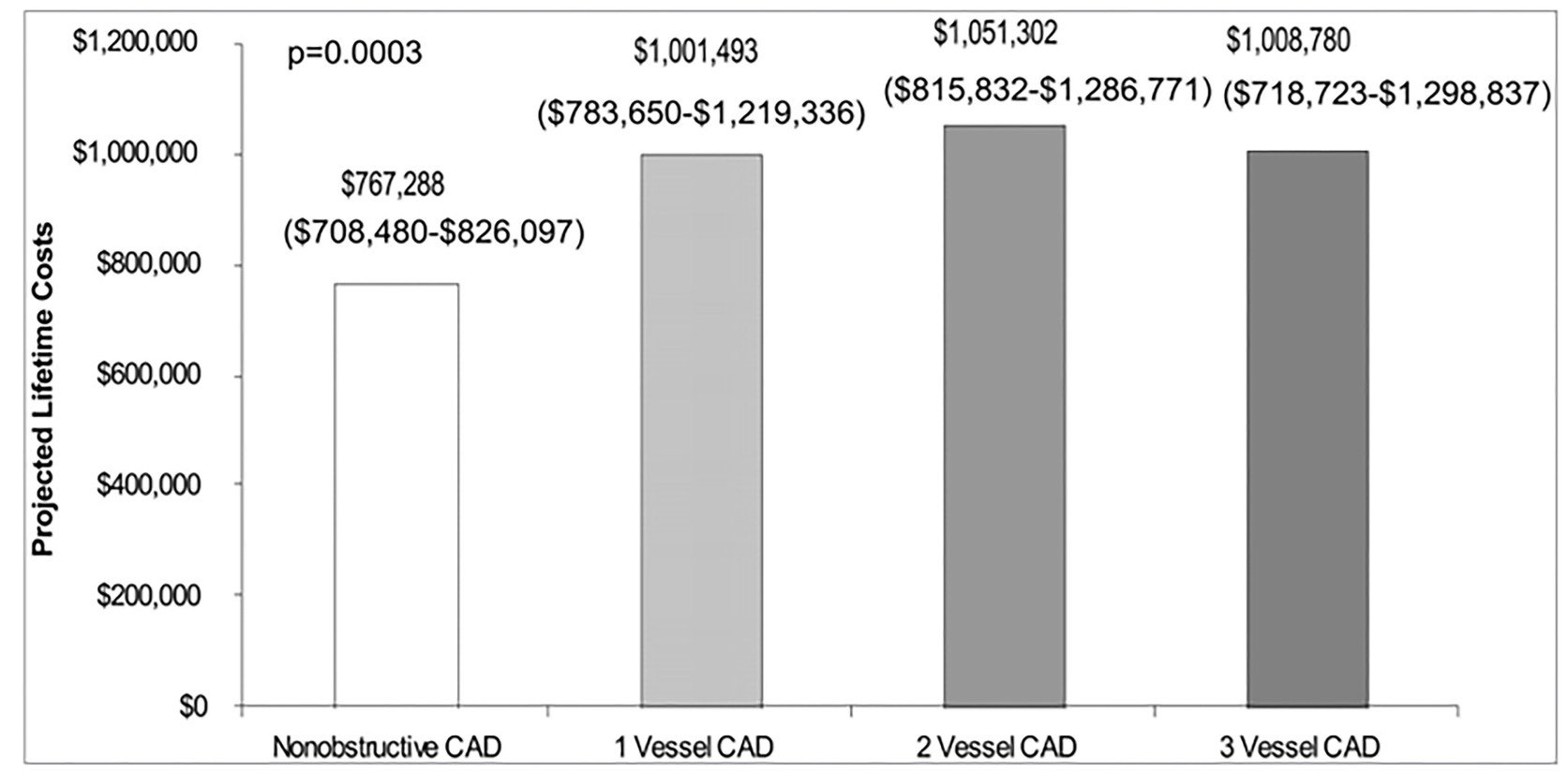

FIGURE 5 | The economic burden of angina in women with suspected ischemic heart disease. Estimated lifetime costs (including sensitivity analyses ranges) of pharmacologic therapy and hospitalization for cardiovascular disease in women with non-obstructive and 1-vessel to 3-vessel CAD. Reprinted with permission (103).

rates (3) in women. Investigation aimed at developing a "female" angina tool, the Women's Ischemia Symptom Questionnaire (WISQ) did not substantially improve diagnostic value (65). Further, we have demonstrated that traditional CAD risk scores underestimate major adverse cardiovascular event rates in women with chest pain and no obstructive CAD (Figure 3) (67).

\section{SEX/GENDER DIFFERENCES IN CHEST PAIN CHARACTERIZATION: TYPICAL AND ATYPICAL ANGINA}

Prior analyses of sex and gender-based differences of angina characterization in ACS have demonstrated varied results, but the majority of studies describe chest pain as the most frequent symptom in both genders (68-70). However, women are more likely to have atypical angina, which can arise after exertion, be triggered by mental stress or even occur at rest (71). In addition, atypical angina may occur not only in the substernal region but also in the arms, jaw, neck, and upper back pain, and these atypical locations are prevalent in women with STEMI (72). Symptoms may last intermittently over several hours, and atypical symptoms may include dyspnea, unusual fatigue, dizziness, and nausea $(73,74)$. Contemporary cohorts demonstrate that the typicality of angina no longer discriminates obstructive CAD. Specifically, there is marked overestimation of obstructive CAD prevalence by the standard probability methods focused on the typicality of angina in both sex and age subgroups, with the most severe overestimation in women (75). Further, we have described likely socio-cultural aspects of chest pain where
Black women who more often ascribe their chest pain to their stomach had a more adverse cardiovascular prognosis in this group (Figure 4) (76). These findings indicate that chest pain "typicality" should no longer guide clinical decisions, particularly in women.

\section{SEX/GENDER IN SILENT ISCHEMIA}

Silent ischemia investigations from ambulatory monitoring demonstrate that more than half of "angina" episodes lack evidence of myocardial ischemia by ECG, while $85 \%$ of ambulatory ischemia (detected by ECG changes) is symptomatically "silent" (77). In obstructive CAD patients majority of chest pain episodes do not have ST depressions on ambulatory ECG monitoring (77-85). In women with CMD diagnosed by invasive coronary function testing, ambulatory ischemia is prevalent based on 24-hour ECG monitoring, but a majority of episodes are silent, and symptoms did not correlate with ST segment changes (86). Further, the severity of ischemia on stress testing does not correlate with angina burden $(84,87-$ 89). Low heart rate variability is associated with myocardial ischemia, implicating cardiac ANS in the pathophysiology of ischemia $(90,91)$.

\section{SEX/GENDER IN CHEST PAIN AND ISCHEMIC HEART DISEASE}

Women with evidence of ischemia, identified by objective evidence such as abnormal stress or biomarker testing, are 


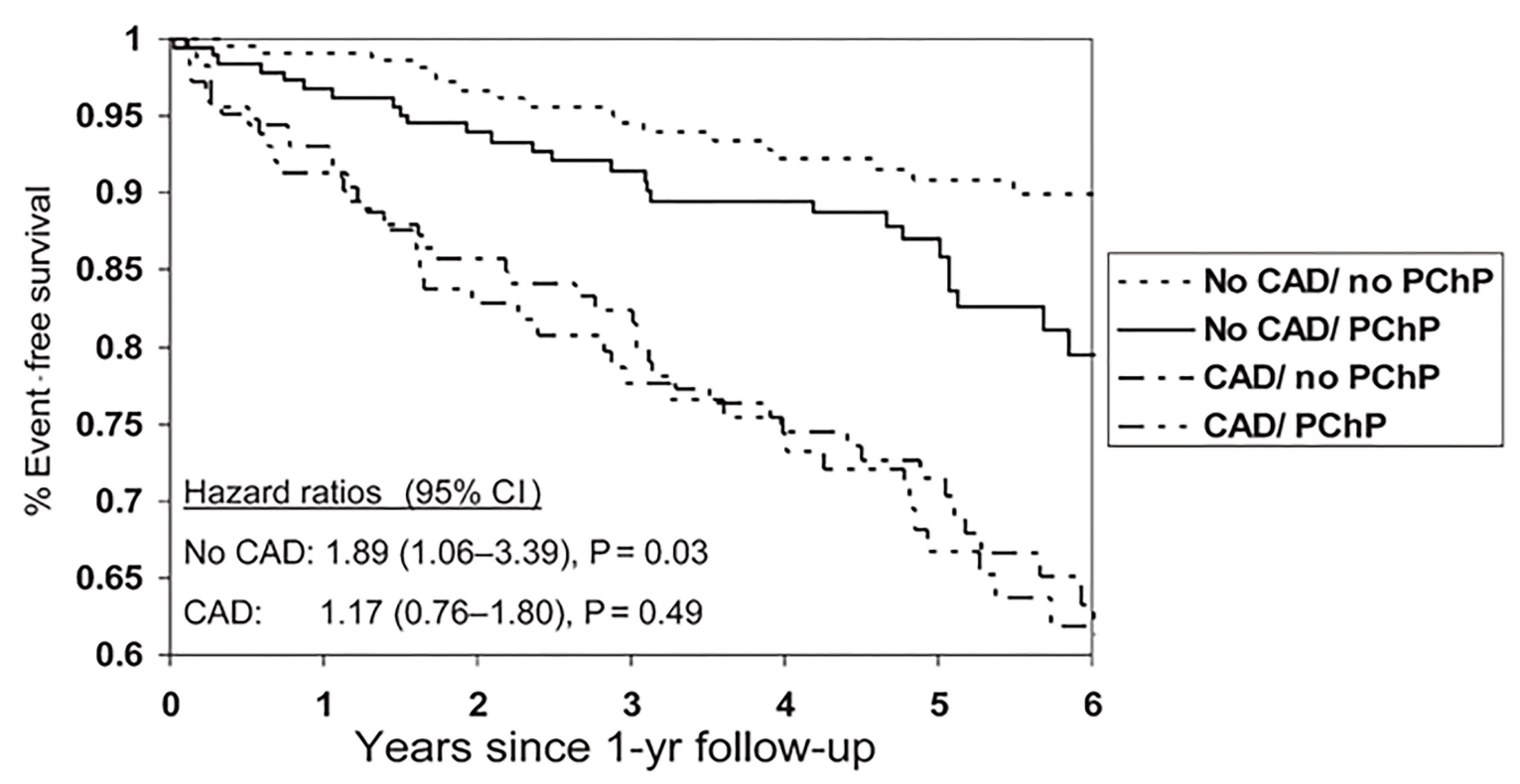

Number at Risk:

$\begin{array}{lrrrrrrr}\text { NoCAD/no PChP } & 223 & 215 & 190 & 173 & 154 & 109 & 65 \\ \text { NoCAD/PChP } & 189 & 179 & 157 & 139 & 128 & 80 & 38 \\ \text { CAD/noPChP } & 145 & 129 & 110 & 96 & 82 & 60 & 33 \\ \text { CAD/PChP } & 116 & 103 & 82 & 73 & 67 & 46 & 22\end{array}$

FIGURE 6 | Event-free survival from cardiovascular events by coronary artery disease and persistent chest pain. Cardiovascular events for women with and without persistent chest pain (PChP) in subgroups with and without obstructive CAD. Cardiovascular events defined as cardiovascular death, MI, CHF, or stroke. Reprinted with permission (105).

more likely to present with no obstructive coronary arteries (INOCA) compared to men, although women report more chest pain. Traditionally, the presence of ischemic ECG changes in the absence of wall motion abnormalities on stress echocardiography is labeled as a "false-positive" stress test, but emerging data indicate that abnormal stress ECG regardless of echocardiographic response should be considered prognostic (92-94). Additional investigations should be considered to evaluate CMD and vasospasm, as ischemic ECG changes have high specificity for CMD in patients with non-obstructive CAD (95) and a high prevalence of coronary vasospasm is found in patients with typical exertional angina (96).

Among patients with no obstructive CAD, endothelial dysfunction is independently associated with ischemia on stress imaging, but not with symptoms (97). Similarly, impaired coronary flow reserve is often detected in women with angina but no obstructive CAD using various invasive and non-invasive modalities $(36,38,98,99)$, but flow reserve has not been found to be associated with angina burden in women (100). However, women with angina and CMD have reduced exercise capacity compared to asymptomatic women (101). The gap between angina and identifiable ischemia on stress testing has contributed to women without obstructive CAD being diagnosed with non-cardiac chest pain, and discharged from subspecialty care and treatment (102). We have demonstrated chest pain hospitalization rates continue at a relatively constant rate in INOCA women despite medical advances (Figure 5) (104), suggesting inertia in this area. Notably, lifetime healthcare costs of chest pain in the setting of INOCA with non-obstructive $\mathrm{CAD}$ are close to the costs of obstructive CAD in women (Figure 6) (103).

Women are also more likely to present with myocardial infarction with non-obstructive coronary artery disease (MINOCA) (106) Recent study found that a cause of MINOCA was identified in $84.5 \%$ of the women who underwent multi-modality imaging (98/116) including optical coherence tomography (OCT) and cardiac magnetic resonance imaging (CMRI). On CMRI an ischemic pattern was present in 53.4\% of participants, while a non-ischemic pattern (myocarditis, takotsubo syndrome or non-ischemic cardiomyopathy) was present in $20.7 \%$ (107) In the CIAO-ISCHEMIA (Changes in Ischemia and Angina over One year in ISCHEMIA trial screen failures with INOCA) cohort study, ischemia by stress echocardiography did not correlate with angina (108). However, in a randomized placebo-controlled clinical trial with ranolazine, change in myocardial perfusion reserve index 


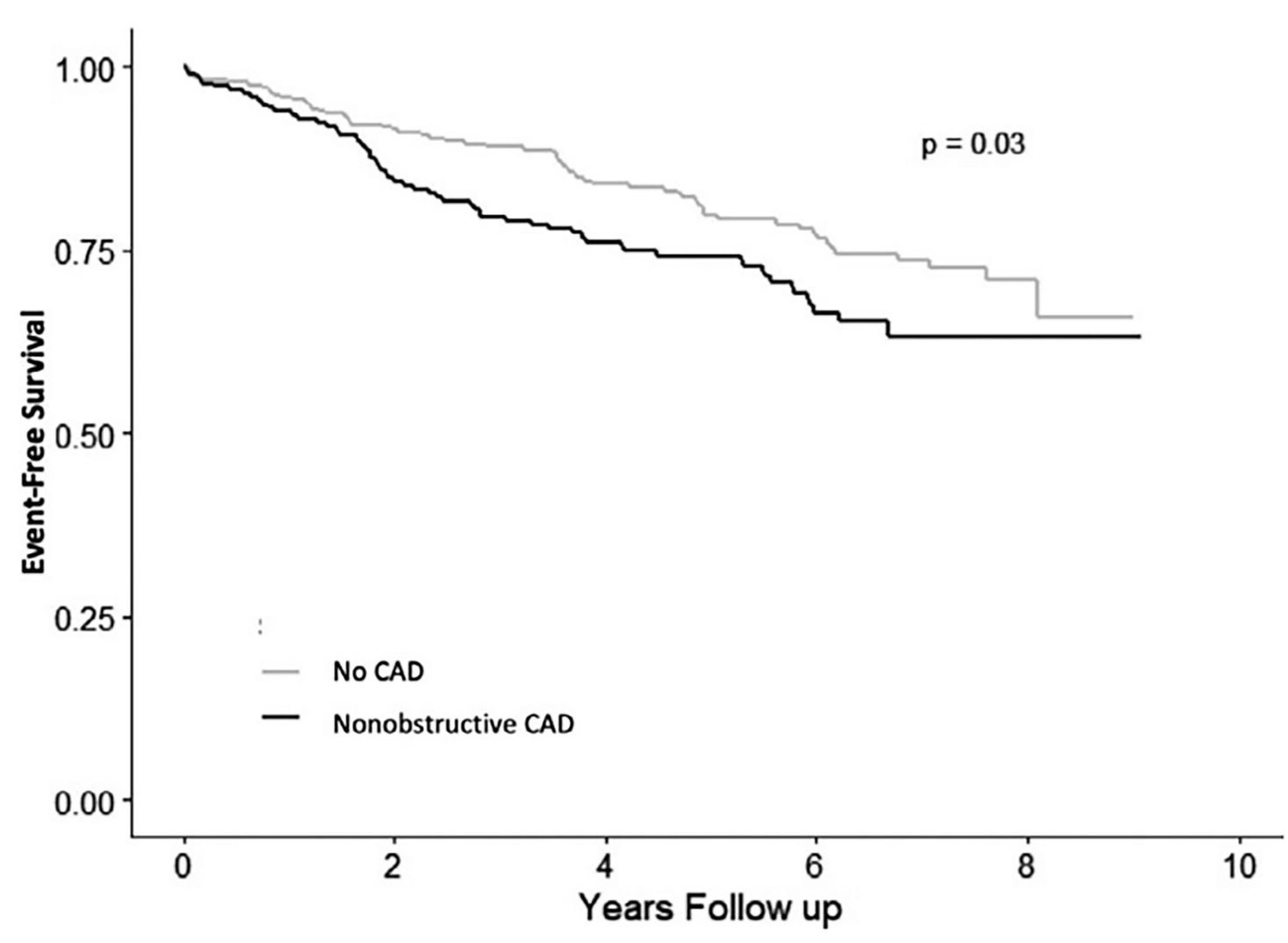

FIGURE 7 | Angina hospitalization rates in women with signs and symptoms of ischemia but no obstructive CAD. Angina hospitalization event-free survival in women with no CAD ( $<20 \%$ stenosis) and non-obstructive CAD ( $\geq 20$ to $<50 \%$ stenosis). Reprinted with permission (104).

directly correlated with change in angina measured by the Seattle Angina Questionnaire, supporting a link between symptoms and microvascular ischemia in women with INOCA (109).

Invasive coronary function testing can diagnose coronary vascular dysfunction (epicardial and microvascular) in patients with persistent angina with and without obstructive CAD (98). Guided treatment of microvascular vs. vasospastic angina has been demonstrated to improve angina outcomes (110). Even in the setting of obstructive $\mathrm{CAD}$, chest pain persists up to $40 \%$ of patients post-percutaneous coronary intervention (PCI) at 1-year follow-up (111). The relationships between epicardial atherosclerotic burden and microcirculatory dysfunction needs further investigation, since it is possible that a subset of patients with persistent angina despite PCI may be experiencing CMDrelated ischemia (112).

Recently findings from an international cohort study of patients with microvascular angina ( $n=686,64 \%$ women) showed that CMD is associated with significant MACE in both men and women, but women have lower quality of life compared to men (113). We have demonstrated that persistent chest pain in the absence of obstructive CAD has an adverse prognosis in women (Figure 7) (105), and atypical angina further worsens that prognosis in women (114), presumably due to a lack of recognition and treatment for underlying ischemia. Lack of recognition of sex and gender differences in chest pain may in part explain outcome disparities in women compared to men (115). CAD outcomes for women may be improved by improved provider and patient education (116, 117), standardized protocols (16), and sex-specific understanding of ischemic heart disease pathophysiology $(37,118)$.

\section{SEX AND GENDER CHEST PAIN KNOWLEDGE GAPS}

Why do women have more chest pain compared to men, despite paradoxically having less obstructive CAD? Despite evidence of psychological factors contributing to angina, the brain correlates contributing to sex-differences in autonomic reactivity and persistent angina are unknown. Furthermore, whether neural mechanistic pathways can be effectively modulated to reduce angina burden and cardiovascular outcomes remains to be investigated. The biological pathways of how repetitive and cumulative chronic psychosocial stress burden over time may predispose to future angina development are unclear, especially in the context of sex differences as well as social determinants of health. The contribution of ANS activation during acute mental stress with resultant cardiovascular stress response needs to be investigated. Investigation is needed to determine whether 
brain activation/deactivation responses to visceral pain differ across CMD and vasospastic angina subtypes and varying degrees of CAD severity, and in comparison, to asymptomatic groups with obstructive CAD. Novel approaches that collect real-time data of daily life stress paired with autonomic output measured using wearable technology may be the next frontier to really understand psychological stress reactivity and angina. Neuroendocrine axis disruption and inflammation as contributors to abnormal microvascular reactivity and angina in women remains to be rigorously tested. Clarifying how physiologic responses to mental stress are influenced by underlying psychological risk factors and their contribution to chest pain burden will help guide novel angina treatment strategies. Mechanistic human studies should involve interdisciplinary investigation among cardiologists, neuroscientists, bio-behavioral specialists, and pain specialists to improve chest pain understanding and treatment.

\section{CONCLUSIONS/IMPLICATIONS}

The presence of persistent clinically meaningful sex and gender differences in the cardiovascular disease detection and management continues to result in cardiovascular health outcome disparities for women (119). A socio-cultural genderbias with regard to lack of recognition of sex-differences in chest pain symptoms appear to contribute to the adverse outcome

\section{REFERENCES}

1. Benjamin EJ, Muntner P, Alonso A, Bittencourt MS, Callaway CW, Carson AP, et al. Heart disease and stroke statistics-2019 update: a report from the American Heart Association. Circulation. (2019) 139:e56528. doi: 10.1161/CIR.0000000000000659

2. Timmis A, Townsend N, Gale C, Grobbee R, Maniadakis N, Flather M, et al. European society of cardiology: cardiovascular disease statistics 2017. Eur Heart J. (2018) 39:508-79. doi: 10.1093/eurheartj/ehx628

3. Bugiardini R, Ricci B, Cenko E, Vasiljevic Z, Kedev S, Davidovic $\mathrm{G}$, et al. Delayed care and mortality among women and men with myocardial infarction. J Am Heart Assoc. (2017) 6:e005968. doi: 10.1161/JAHA.117.005968

4. Dreyer RP, Beltrame JF, Tavella R, Air T, Hoffmann B, Pati PK, et al. Evaluation of gender differences in Door-to-Balloon time in ST-elevation myocardial infarction. Heart Lung Circ. (2013) 22:8619. doi: 10.1016/j.hlc.2013.03.078

5. Virani SS, Woodard LD, Ramsey DJ, Urech TH, Akeroyd JM, Shah T, et al. Gender disparities in evidence-based statin therapy in patients with cardiovascular disease. Am J Cardiol. (2015) 115:21-6. doi: 10.1016/j.amjcard.2014.09.041

6. Mosca L, Linfante AH, Benjamin EJ, Berra K, Hayes SN, Walsh BW, et al. National study of physician awareness and adherence to cardiovascular disease prevention guidelines. Circulation. (2005) 111:499510. doi: 10.1161/01.CIR.0000154568.43333.82

7. Scott PE, Unger EF, Jenkins MR, Southworth MR, McDowell TY, Geller RJ, et al. Participation of women in clinical trials supporting FDA approval of cardiovascular drugs. J Am Coll Cardiol. (2018) 71:19609. doi: 10.1016/j.jacc.2018.02.070

8. Shah T, Haimi I, Yang Y, Gaston S, Taoutel R, Mehta S, et al. Meta-Analysis of gender disparities in in-hospital care and outcomes in patients with ST-segment elevation myocardial infarction. Am J Cardiol. (2021) 147:2332. doi: 10.1016/j.amjcard.2021.02.015 differences in women compared to men. Since chest pain often does not correlate with myocardial ischemia or obstructive $\mathrm{CAD}$, a greater understanding of chest pain etiologies and CMD-specific diagnostic testing will assist with appropriate use of interventional and medical angina treatment strategies. Further investigation is needed to understand sex and gender differences in chest pain, including biological pathways as well as sociocultural contributions, to improve clinical care. Increased awareness, education, and treatment to improve the prevention of cardiovascular disease in both women and men are needed.

\section{AUTHOR CONTRIBUTIONS}

PM, JW, CS, OQ, LS, and CB have made a substantial, direct and intellectual contribution to the work, and approved it for publication.

\section{FUNDING}

This work was supported by K23HL105787, K23HL151867, 1U54AG062334, the Edythe L. Broad Women's Heart Research Fellowship, the Constance Austin Women's Heart Research Fellowship, the Erika J. Glazer Women's Heart Research Initiative, and the Barbra Streisand Women's Cardiovascular Research and Education Program, Cedars-Sinai Medical Center, Los Angeles.
9. Shahin M, Obeid S, Hamed L, Templin C, Gamperli O, Nietlispach F, et al. Occurrence and impact of time delay to primary percutaneous coronary intervention in patients with ST-segment elevation myocardial infarction. Cardiol Res. (2017) 8:190-8. doi: 10.14740/cr612w

10. Mahmoud KD, Gu YL, Nijsten MW, de Vos R, Nieuwland W, Zijlstra $\mathrm{F}$, et al. Interhospital transfer due to failed prehospital diagnosis for primary percutaneous coronary intervention: an observational study on incidence, predictors, and clinical impact. Eur Heart J Acute Cardiovasc Care. (2013) 2:166-75. doi: 10.1177/20488726134 81449

11. Melberg T, Kindervaag B, Rosland J. Gender-specific ambulance priority and delays to primary percutaneous coronary intervention: a consequence of the patients' presentation or the management at the emergency medical communications center? Am Heart J. (2013) 166:839-45. doi: 10.1016/j.ahj.2013.07.034

12. D’Onofrio G, Safdar B, Lichtman JH, Strait KM, Dreyer RP, Geda M, et al. Sex differences in reperfusion in young patients with ST-segment-elevation myocardial infarction: results from the VIRGO study. Circulation. (2015) 131:1324-32. doi: 10.1161/CIRCULATIONAHA.114.012293

13. Ya'qoub L, Lemor A, Dabbagh M, O’Neill W, Khandelwal A, Martinez SC, et al. Racial, ethnic, and sex disparities in patients with STEMI and cardiogenic shock. JACC Cardiovasc Interv. (2021) 14:653-60. doi: 10.1016/j.jcin.2021.01.003

14. Bugiardini R, Bairey Merz CN. Angina with "normal" coronary arteries: a changing philosophy. JAMA. (2005) 293:47784. doi: 10.1001/jama.293.4.477

15. Ghadri JR, Sarcon A, Jaguszewski M, Diekmann J, Bataiosu RD, Hellermann J, et al. Gender disparities in acute coronary syndrome: a closing gap in the short-term outcome. $J$ Cardiovasc Med. (2015) 16:355-62. doi: 10.2459/JCM.00000000000 00248

16. Wei J, Mehta PK, Grey E, Garberich RF, Hauser R, Bairey Merz CN, et al. Sex-based differences in quality of care and outcomes in a health 
system using a standardized STEMI protocol. Am Heart J. (2017) 191:306. doi: 10.1016/j.ahj.2017.06.005

17. Roswell RO, Kunkes J, Chen AY, Chiswell K, Iqbal S, Roe MT, et al. Impact of sex and contact-to-device time on clinical outcomes in acute ST-segment elevation myocardial infarction-findings from the national cardiovascular data registry. J Am Heart Assoc. (2017) 6:e004521. doi: 10.1161/JAHA.116.004521

18. Clayton JA, Collins FS. Policy: NIH to balance sex in cell and animal studies. Nature. (2014) 509:282-3. doi: 10.1038/509282a

19. Virani SS, Alonso A, Aparicio HJ, Benjamin EJ, Bittencourt MS, Callaway $\mathrm{CW}$, et al. Heart disease and stroke statistics-2021 update: a report from the American Heart Association. Circulation. (2021) 143:e254743. doi: 10.1161/CIR.0000000000000950

20. Mehta PK, Bess C, Elias-Smale S, Vaccarino V, Quyyumi A, Pepine CJ, et al. Gender in cardiovascular medicine: chest pain and coronary artery disease. Eur Heart J. (2019) 40:3819-26. doi: 10.1093/eurheartj/ehz784

21. Vaccarino V, Shah AJ, Mehta PK, Pearce B, Raggi P, Bremner JD, et al. Brain-heart connections in stress and cardiovascular disease: implications for the cardiac patient. Atherosclerosis. (2021) 328:7482. doi: 10.1016/j.atherosclerosis.2021.05.020

22. Bartley EJ, Fillingim RB. Sex differences in pain: a brief review of clinical and experimental findings. Br J Anaesth. (2013) 111:52-8. doi: 10.1093/bja/aet127

23. Fillingim RB, Ness TJ. Sex-related hormonal influences on pain and analgesic responses. Neurosci Biobehav Rev. (2000) 24:485-501. doi: 10.1016/S0149-7634(00)00017-8

24. Samulowitz A, Gremyr I, Eriksson E, Hensing G. "Brave Men" and "Emotional Women": a theory-guided literature review on gender bias in health care and gendered norms towards patients with chronic pain. Pain Res Manag. (2018) 2018:6358624. doi: 10.1155/2018/6358624

25. Mogil JS. Sex differences in pain and pain inhibition: multiple explanations of a controversial phenomenon. Nat Rev Neurosci. (2012) 13:85966. doi: $10.1038 / \mathrm{nrn} 3360$

26. Arnold SV, Spertus JA, Ciechanowski PS, Soine LA, JordanKeith K, Caldwell JH, et al. Psychosocial modulators of angina response to myocardial ischemia. Circulation. (2009) 120:126-33. doi: 10.1161/CIRCULATIONAHA.108.806034

27. Hayek SS, Ko YA, Awad M, Del Mar Soto A, Ahmed H, Patel K, et al. Depression and chest pain in patients with coronary artery disease. Int $J$ Cardiol. (2017) 230:420-6. doi: 10.1016/j.ijcard.2016.12.091

28. Yusuf S, Hawken S, Ounpuu S, Dans T, Avezum A, Lanas F, et al. Effect of potentially modifiable risk factors associated with myocardial infarction in 52 countries (the INTERHEART study): case-control study. Lancet. (2004) 364:937-52. doi: 10.1016/S0140-6736(04)17018-9

29. Sumner JA, Kubzansky LD, Elkind MS, Roberts AL, Agnew-Blais J, Chen Q, et al. Trauma exposure and posttraumatic stress disorder symptoms predict onset of cardiovascular events in women. Circulation. (2015) 132:2519. doi: 10.1161/CIRCULATIONAHA.114.014492

30. Wei J, Pimple P, Shah AJ, Rooks C, Bremner JD, Nye JA, et al. Depressive symptoms are associated with mental stress-induced myocardial ischemia after acute myocardial infarction. PLoS One. (2014) 9:e102986. doi: 10.1371/journal.pone.0102986

31. Pimple P, Hammadah M, Wilmot K, Ramadan R, Al Mheid I, Levantsevych $\mathrm{O}$, et al. Chest pain and mental stress-induced myocardial ischemia: sex differences. Am J Med. (2018) 131:540-7. doi: 10.1016/j.amjmed.2017.11.026

32. Vaccarino V, Sullivan S, Hammadah M, Wilmot K, Al Mheid I, Ramadan $\mathrm{R}$, et al. Mental stress-induced-myocardial ischemia in young patients with recent myocardial infarction: sex differences and mechanisms. Circulation. (2018) 137:794-805. doi: 10.1161/CIRCULATIONAHA.117.030849

33. Vaccarino V, Wilmot K, Al Mheid I, Ramadan R, Pimple P, Shah AJ, et al. Sex differences in mental stress-induced myocardial ischemia in patients with coronary heart disease. J Am Heart Assoc. (2016) 5:e003630. doi: 10.1161/JAHA.116.003630

34. Hammadah M, Alkhoder A, Al Mheid I, Wilmot K, Isakadze N, Abdulhadi $\mathrm{N}$, et al. Hemodynamic, catecholamine, vasomotor and vascular responses: determinants of myocardial ischemia during mental stress. Int J Cardiol. (2017) 243:47-53. doi: 10.1016/j.ijcard.2017.05.093

35. Mehta PK, Hermel M, Nelson MD, Cook-Wiens G, Martin EA, Alkhoder AA, et al. Mental stress peripheral vascular reactivity is elevated in women with coronary vascular dysfunction: results from the NHLBI-sponsored Cardiac Autonomic Nervous System (CANS) study. Int J Cardiol. (2018) 251:8-13. doi: 10.1016/j.ijcard.2017.10.061

36. Wei J, Mehta PK, Johnson BD, Samuels B, Kar S, Anderson RD, et al. Safety of coronary reactivity testing in women with no obstructive coronary artery disease: results from the NHLBI-sponsored WISE (Women's Ischemia Syndrome Evaluation) study. JACC Cardiovasc Interv. (2012) 5:646-53. doi: 10.1016/j.jcin.2012.01.023

37. Bairey Merz CN, Pepine CJ, Walsh MN, Fleg JL. Ischemia and No Obstructive Coronary Artery Disease (INOCA): developing evidence-based therapies and research agenda for the next decade. Circulation. (2017) 135:1075-92. doi: 10.1161/CIRCULATIONAHA.116.024534

38. Murthy VL, Naya $M$, Taqueti VR, Foster CR, Gaber $M$, Hainer J, et al. Effects of sex on coronary microvascular dysfunction and cardiac outcomes. Circulation. (2014) 129:251827. doi: 10.1161/CIRCULATIONAHA.113.008507

39. Sara JD, Widmer RJ, Matsuzawa Y, Lennon RJ, Lerman LO, Lerman A. Prevalence of coronary microvascular dysfunction among patients with chest pain and nonobstructive coronary artery disease. JACC Cardiovasc Interv. (2015) 8:1445-53. doi: 10.1016/j.jcin.2015.06.017

40. Lee BK, Lim HS, Fearon WF, Yong AS, Yamada R, Tanaka S, et al. Invasive evaluation of patients with angina in the absence of obstructive coronary artery disease. Circulation. (2015) 131:105460. doi: 10.1161/CIRCULATIONAHA.114.012636

41. Kip KE, Marroquin OC, Shaw LJ, Arant CB, Wessel TR, Olson MB, et al. Global inflammation predicts cardiovascular risk in women: a report from the Women's Ischemia Syndrome Evaluation (WISE) study. Am Heart J. (2005) 150:900-6. doi: 10.1016/j.ahj.2005.02.002

42. Marroquin OC, Kip KE, Mulukutla SR, Ridker PM, Pepine CJ, Tjandrawan T, et al. Inflammation, endothelial cell activation, and coronary microvascular dysfunction in women with chest pain and no obstructive coronary artery disease. Am Heart J. (2005) 150:109-15. doi: 10.1016/j.ahj.2004.08.003

43. Shaw LJ, Bugiardini R, Merz CN. Women and ischemic heart disease: evolving knowledge. J Am Coll Cardiol. (2009) 54:1561-75. doi: 10.1016/j.jacc.2009.04.098

44. Lagerqvist B, Sylven C, Waldenstrom A. Lower threshold for adenosineinduced chest pain in patients with angina and normal coronary angiograms. Br Heart J. (1992) 68:282-5. doi: 10.1136/hrt.68.9.282

45. Frobert O, Arendt-Nielsen L, Bak P, Funch-Jensen P, Peder Bagger J. Pain perception and brain evoked potentials in patients with angina despite normal coronary angiograms. Heart. (1996) 75:436-41. doi: 10.1136/hrt.75.5.436

46. Cannon RO 3rd, Quyyumi AA, Schenke WH, Fananapazir L, Tucker EE, Gaughan AM, et al. Abnormal cardiac sensitivity in patients with chest pain and normal coronary arteries. J Am Coll Cardiol. (1990) 16:135966. doi: 10.1016/0735-1097(90)90377-2

47. Cannon RO III. The sensitive heart. a syndrome of abnormal cardiac pain perception. JAMA. (1995) 273:883-7. doi: 10.1001/jama.273.11.883

48. Leach A, Fisher M. Myocardial ischaemia and cardiac pain - a mysterious relationship. Br J Pain. (2013) 7:23-30. doi: 10.1177/2049463712474648

49. Harrison NA, Cooper E, Voon V, Miles K, Critchley HD. Central autonomic network mediates cardiovascular responses to acute inflammation: relevance to increased cardiovascular risk in depression? Brain Behav Immun. (2013) 31:189-96. doi: 10.1016/j.bbi.2013.02.001

50. Gianaros PJ, Sheu LK. A review of neuroimaging studies of stressorevoked blood pressure reactivity: emerging evidence for a brain-body pathway to coronary heart disease risk. Neuroimage. (2009) 47:92236. doi: 10.1016/j.neuroimage.2009.04.073

51. Rosen SD, Camici PG. The brain-heart axis in the perception of cardiac pain: the elusive link between ischaemia and pain. Ann Med. (2000) 32:35064. doi: $10.3109 / 07853890008995938$

52. Rosen SD, Paulesu E, Nihoyannopoulos P, Tousoulis D, Frackowiak RS, Frith $\mathrm{CD}$, et al. Silent ischemia as a central problem: regional brain activation compared in silent and painful myocardial ischemia. Ann Intern Med. (1996) 124:939-49. doi: 10.7326/0003-4819-124-11-199606010-00001

53. Bremner JD, Campanella C, Khan Z, Shah M, Hammadah M, Wilmot K, et al. Brain correlates of mental stress-induced myocardial ischemia. Psychosom Med. (2018) 80:515-25. doi: 10.1097/PSY.0000000000000597 
54. Devinsky O, Morrell MJ, Vogt BA. Contributions of anterior cingulate cortex to behaviour. Brain. (1995) 118:279-306. doi: 10.1093/brain/118.1.279

55. Vogt BA, Finch DM, Olson CR. Functional heterogeneity in cingulate cortex: the anterior executive and posterior evaluative regions. Cereb Cortex. (1992) 2:435-43. doi: 10.1093/cercor/2.6.435-a

56. Zheng L, Ning R, Li L, Wei C, Cheng X, Zhou C, et al. Gender differences in behavioral and neural responses to unfairness under social pressure. Sci Rep. (2017) 7:13498. doi: 10.1038/s41598-017-13790-6

57. Radfar A, Abohashem S, Osborne MT, Wang Y, Dar T, Hassan MZO, et al. Stress-associated neurobiological activity associates with the risk for and timing of subsequent Takotsubo syndrome. Eur Heart J. (2021) 42:1898908. doi: 10.1093/eurheartj/ehab029

58. van Oosterhout REM, de Boer AR, Maas A, Rutten FH, Bots ML, Peters SAE. Sex differences in symptom presentation in acute coronary syndromes: a systematic review and meta-analysis. J Am Heart Assoc. (2020) 9:e014733. doi: 10.1161/JAHA.119.014733

59. Hemal K, Pagidipati NJ, Coles A, Dolor RJ, Mark DB, Pellikka PA, et al. Sex differences in demographics, risk factors, presentation, and noninvasive testing in stable outpatients with suspected coronary artery disease: insights from the PROMISE trial. JACC Cardiovasc Imaging. (2016) 9:337-46. doi: 10.1016/j.jcmg.2016.02.001

60. Harris RB, Weissfeld LA. Gender differences in the reliability of reporting symptoms of angina pectoris. J Clin Epidemiol. (1991) 44:10718. doi: 10.1016/0895-4356(91)90009-X

61. Zhang Y, Liu Y, Zhang $H$, Zhou J. Impact of sex-specific differences in calculating the pretest probability of obstructive coronary artery disease in symptomatic patients: a coronary computed tomographic angiography study. Coron Artery Dis. (2019) 30:124-30. doi: 10.1097/MCA.0000000000000696

62. Sacks D, Baxter B, Campbell BCV, Carpenter JS, Cognard C, Dippel D, et al. Multisociety consensus quality improvement revised consensus statement for endovascular therapy of acute ischemic stroke: from the American Association of Neurological Surgeons (AANS), American Society of Neuroradiology (ASNR), Cardiovascular and Interventional Radiology Society of Europe (CIRSE), Canadian Interventional Radiology Association (CIRA), Congress of Neurological Surgeons (CNS), European Society of Minimally Invasive Neurological Therapy (ESMINT), European Society of Neuroradiology (ESNR), European Stroke Organization (ESO), Society for Cardiovascular Angiography and Interventions (SCAI), Society of Interventional Radiology (SIR), Society of NeuroInterventional Surgery (SNIS), and World Stroke Organization (WSO). J Vasc Interv Radiol. (2018) 29:441-53. doi: 10.1016/j.jvir.2017.11.026

63. Norris CM, Johnson NL, Hardwicke-Brown E, McEwan M, Pelletier R, Pilote L. The contribution of gender to apparent sex differences in health status among patients with coronary artery disease. J Womens Health. (2017) 26:50-7. doi: 10.1089/jwh.2016.5744

64. Pope JH, Aufderheide TP, Ruthazer R, Woolard RH, Feldman JA, Beshansky JR, et al. Missed diagnoses of acute cardiac ischemia in the emergency department. $N$ Engl J Med. (2000) 342:1163-70. doi: 10.1056/NEJM200004203421603

65. Mehta PK, Sharma S, Minissian M, Harsch MR, Martinson M, Nyman JA, et al. Ranolazine reduces angina in women with ischemic heart disease: results of an open-label, multicenter trial. J Womens Health. (2019) 28:57382. doi: $10.1089 /$ jwh. 2018.7019

66. Sedlak T, Herscovici R, Cook-Wiens G, Handberg E, Wei J, Shufelt $\mathrm{C}$, et al. Predicted versus observed major adverse cardiac event risk in women with evidence of Ischemia and No Obstructive Coronary Artery disease: a report from WISE (Women's Ischemia Syndrome Evaluation). J Am Heart Assoc. (2020) 9:e013234. doi: 10.1161/JAHA.119.0 13234

67. Herscovici R, Sedlak T, Wei J, Pepine CJ, Handberg E, Bairey Merz CN. Ischemia and No Obstructive Coronary Artery Disease (INOCA): what is the risk? J Am Heart Assoc. (2018) 7:e008868. doi: 10.1161/JAHA.118.0 08868

68. Araújo $\mathrm{C}$, Laszczyńska $\mathrm{O}$, Viana $\mathrm{M}$, Melão $\mathrm{F}$, Henriques $\mathrm{A}$, Borges A, et al. Sex differences in presenting symptoms of acute coronary syndrome: the EPIHeart cohort study. BMJ Open. (2018) 8:e018798. doi: 10.1136/bmjopen-2017-018798
69. Arslanian-Engoren C, Patel A, Fang J, Armstrong D, KlineRogers E, Duvernoy CS, et al. Symptoms of men and women presenting with acute coronary syndromes. Am J Cardiol. (2006) 98:1177-81. doi: 10.1016/j.amjcard.2006.05.049

70. Lichtman JH, Leifheit EC, Safdar B, Bao H, Krumholz HM, Lorenze NP, et al. Sex differences in the presentation and perception of symptoms among young patients with myocardial infarction: evidence from the VIRGO Study (Variation in Recovery: Role of Gender on Outcomes of Young AMI Patients). Circulation. (2018) 137:78190. doi: 10.1161/CIRCULATIONAHA.117.031650

71. Wenger NK. Clinical presentation of CAD and myocardial ischemia in women. J Nucl Cardiol. (2016) 23:976-85. doi: 10.1007/s12350-016-0593-1

72. Sederholm Lawesson S, Isaksson RM, Thylen I, Ericsson M, Angerud K, Swahn E, et al. Gender differences in symptom presentation of ST-elevation myocardial infarction - an observational multicenter survey study. Int $J$ Cardiol. (2018) 264:7-11. doi: 10.1016/j.ijcard.2018.03.084

73. Lichtman JH, Leifheit-Limson EC, Watanabe E, Allen NB, Garavalia B, Garavalia LS, et al. Symptom recognition and healthcare experiences of young women with acute myocardial infarction. Circ Cardiovasc Qual Outcomes. (2015) 8(2 Suppl. 1):S31-8. doi: 10.1161/CIRCOUTCOMES.114.001612

74. Nugent L, Mehta PK, Bairey Merz CN. Gender and microvascular angina. $J$ Thromb Thrombolysis. (2011) 31:37-46. doi: 10.1007/s11239-010-0477-1

75. Cheng VY, Berman DS, Rozanski A, Dunning AM, Achenbach S, Al-Mallah $\mathrm{M}$, et al. Performance of the traditional age, sex, and angina typicalitybased approach for estimating pretest probability of angiographically significant coronary artery disease in patients undergoing coronary computed tomographic angiography: results from the multinational coronary CT angiography evaluation for clinical outcomes: an international multicenter registry (CONFIRM). Circulation. (2011) 124:2423-32:24218. doi: 10.1161/CIRCULATIONAHA.111.039255

76. Eastwood JA, Johnson BD, Rutledge T, Bittner V, Whittaker KS, Krantz DS, et al. Anginal symptoms, coronary artery disease, and adverse outcomes in Black and White women: the NHLBI-sponsored Women's Ischemia Syndrome Evaluation (WISE) study. J Womens Health. (2013) 22:72432. doi: 10.1089/jwh.2012.4031

77. Krantz DS, Hedges SM, Gabbay FH, Klein J, Falconer JJ, Merz CN, et al. Triggers of angina and ST-segment depression in ambulatory patients with coronary artery disease: evidence for an uncoupling of angina and ischemia. Am Heart J. (1994) 128:703-12. doi: 10.1016/0002-8703(94)90268-2

78. Pepine CJ. Does the brain know when the heart is ischemic? Ann Intern Med. (1996) 124:1006-8. doi: 10.7326/0003-4819-124-11-199606010-00009

79. Schang SJ Jr, Pepine CJ. Transient asymptomatic S-T segment depression during daily activity. Am J Cardiol. (1977) 39:396402. doi: 10.1016/S0002-9149(77)80095-7

80. Gottlieb SO, Gottlieb SH, Achuff SC, Baumgardner R, Mellits ED, Weisfeldt ML, et al. Silent ischemia on Holter monitoring predicts mortality in high-risk postinfarction patients. JAMA. (1988) 259:10305. doi: 10.1001/jama.259.7.1030

81. Aronow WS, Epstein S. Usefulness of silent myocardial ischemia detected by ambulatory electrocardiographic monitoring in predicting new coronary events in elderly patients. Am J Cardiol. (1988) 62:12956. doi: 10.1016/0002-9149(88)90277-9

82. Langer A, Freeman MR, Armstrong PW. ST segment shift in unstable angina: pathophysiology and association with coronary anatomy and hospital outcome. J Am Coll Cardiol. (1989) 13:1495-502. doi: 10.1016/0735-1097(89)90338-0

83. Bugiardini R, Borghi A, Pozzati A, Ruggeri A, Puddu P, Maseri A. Relation of severity of symptoms to transient myocardial ischemia and prognosis in unstable angina. J Am Coll Cardiol. (1995) 25:597604. doi: 10.1016/0735-1097(94)00439-W

84. Quyyumi AA, Mockus L, Wright C, Fox KM. Morphology of ambulatory ST segment changes in patients with varying severity of coronary artery disease. investigation of the frequency of nocturnal ischaemia and coronary spasm. Br Heart J. (1985) 53:186-93. doi: 10.1136/hrt.53.2.186

85. Deedwania PC, Carbajal EV. Silent ischemia during daily life is an independent predictor of mortality in stable angina. Circulation. (1990) 81:748-56. doi: 10.1161/01.CIR.81.3.748 
86. Roy R, Aldiwani H, Darouian N, Sharma S, Torbati T, Wei J, et al. Ambulatory and silent myocardial ischemia in women with coronary microvascular dysfunction: results from the Cardiac Autonomic Nervous System study (CANS). Int J Cardiol. (2020) 316:1-6. doi: 10.1016/j.ijcard.2020.04.030

87. Quyyumi A. What causes silent myocardial ischemia? Postgrad Med. (1989) 86:62-6:69-75. doi: 10.1080/00325481.1989.11700773

88. Nakanishi R, Rana JS, Rozanski A, Cheng VY, Gransar H, Thomson LE, et al. Relationship of dyspnea vs. typical angina to coronary artery disease severity, burden, composition and location on coronary CT angiography. Atherosclerosis. (2013) 230:61-6. doi: 10.1016/j.atherosclerosis.2013. 06.008

89. Steg PG, Greenlaw N, Tendera M, Tardif JC, Ferrari R, Al-Zaibag M, et al. Prevalence of anginal symptoms and myocardial ischemia and their effect on clinical outcomes in outpatients with stable coronary artery disease: data from the International Observational CLARIFY Registry. JAMA Intern Med. (2014) 174:1651-9. doi: 10.1001/jamainternmed.2014. 3773

90. Goseki Y, Matsubara T, Takahashi N, Takeuchi T, Ibukiyama C. Heart rate variability before the occurrence of silent myocardial ischemia during ambulatory monitoring. Am J Cardiol. (1994) 73:845-9. doi: 10.1016/0002-9149(94)9 0807-9

91. Pardo Y, Merz CN, Paul-Labrador M, Velasquez I, Gottdiener JS, Kop WJ, et al. Heart rate variability reproducibility and stability using commercially available equipment in coronary artery disease with daily life myocardial ischemia. Am J Cardiol. (1996) 78:866-70. doi: 10.1016/S0002-9149(96)0 0458-4

92. Daubert MA, Sivak J, Dunning A, Douglas PS, Coyne B, Wang TY, et al. Implications of abnormal exercise electrocardiography with normal stress echocardiography. JAMA Intern Med. (2020) 180:494-502. doi: 10.1001/jamainternmed.201 9.6958

93. Krivokapich J, Child JS, Walter DO, Garfinkel A. Prognostic value of dobutamine stress echocardiography in predicting cardiac events in patients with known or suspected coronary artery disease. $J$ Am Coll Cardiol. (1999) 33:708-16. doi: 10.1016/S0735-1097(98)0 0632-9

94. Tjoe B, Shufelt C, Wei J, Lauzon M, Lewis J, Pepine C, et al. Association of abnormal electrocardiography response on stress echocardiogram with major adverse cardiovascular events in women: a report from the women's ischemia syndrome evaluation (WISE) study. J Am Coll Cardiol. (2021) 77 (18 Suppl. 1):1349. doi: 10.1016/S0735-1097(21)0 2707-8

95. Cassar A, Chareonthaitawee P, Rihal CS, Prasad A, Lennon RJ, Lerman LO, et al. Lack of correlation between noninvasive stress tests and invasive coronary vasomotor dysfunction in patients with nonobstructive coronary artery disease. Circ Cardiovasc Interv. (2009) 2:237-44. doi: 10.1161/CIRCINTERVENTIONS.108.841056

96. Ong P, Athanasiadis A, Borgulya G, Mahrholdt H, Kaski JC, Sechtem U. High prevalence of a pathological response to acetylcholine testing in patients with stable angina pectoris and unobstructed coronary arteries. the ACOVA Study (Abnormal COronary VAsomotion in patients with stable angina and unobstructed coronary arteries). J Am Coll Cardiol. (2012) 59:65562. doi: 10.1016/j.jacc.2011.11.015

97. Kulshreshtha A, Zheng Y, Quyyumi AA, Veledar E, Votaw J, Uphoff I, et al. Endothelial dysfunction is associated with occult coronary artery disease detected by positron emission tomography. IJC Metab Endocr. (2014) 4:28-32. doi: 10.1016/j.ijcme.2014.07.004

98. Kumar S, Mehta PK, Eshtehardi P, Hung OY, Koh JS, Kumar A, et al. Functional coronary angiography in symptomatic patients with no obstructive coronary artery disease. Catheter Cardiovasc Interv. (2020) 98:217-22. doi: 10.1002/ccd.29237

99. Bechsgaard DF, Gustafsson I, Michelsen MM, Mygind ND, Raft KF, Linde JJ, et al. Evaluation of computed tomography myocardial perfusion in women with angina and no obstructive coronary artery disease. Int J Cardiovasc Imaging. (2020) 36:367-82. doi: 10.1007/s10554-019-01723-5
100. Bove KB, Michelsen MM, Schroder J, Suhrs HE, Bechsgaard DF, Mygind $\mathrm{ND}$, et al. Impaired coronary flow velocity reserve is associated with cardiovascular risk factors but not with angina symptoms. Open Heart. (2021) 8:1-10. doi: 10.1136/openhrt-2020-001486

101. Bechsgaard DF, Hove JD, Suhrs HE, Bove KB, Shahriari P, Gustafsson I, et al. Women with coronary microvascular dysfunction and no obstructive coronary artery disease have reduced exercise capacity. Int J Cardiol. (2019) 293:1-9. doi: 10.1016/j.ijcard.2019.07.048

102. Pacheco Claudio C, Quesada O, Pepine CJ, Noel Bairey Merz C. Why names matter for women: MINOCA/INOCA (myocardial infarction/ischemia and no obstructive coronary artery disease). Clin Cardiol. (2018) 41:18593. doi: $10.1002 /$ clc.22894

103. Shaw LJ, Merz CN, Pepine CJ, Reis SE, Bittner V, Kip KE, et al. The economic burden of angina in women with suspected ischemic heart disease: results from the National Institutes of Health-National Heart, Lung, and Blood Institute-sponsored Women's Ischemia Syndrome Evaluation. Circulation. (2006) 114:894-904. doi: 10.1161/CIRCULATIONAHA.105.609990

104. Aldiwani H, Zaya M, Suppogu N, Quesada O, Johnson BD, Mehta PK, et al. Angina hospitalization rates in women with signs and symptoms of ischemia but no obstructive coronary artery disease: a report from the WISE (Women's Ischemia Syndrome Evaluation) Study. J Am Heart Assoc. (2020) 9:e013168. doi: 10.1161/JAHA.119.013168

105. Johnson BD, Shaw LJ, Pepine CJ, Reis SE, Kelsey SF, Sopko G, et al. Persistent chest pain predicts cardiovascular events in women without obstructive coronary artery disease: results from the NIH-NHLBI-sponsored Women's Ischaemia Syndrome Evaluation (WISE) study. Eur Heart J. (2006) 27:140815. doi: 10.1093/eurheartj/ehl040

106. Tamis-Holland JE, Jneid H, Reynolds HR, Agewall S, Brilakis ES, Brown $\mathrm{TM}$, et al. Contemporary diagnosis and management of patients with myocardial infarction in the absence of obstructive coronary artery disease: a scientific statement from the American Heart Association. Circulation. (2019) 139:e891-908. doi: 10.1161/CIR.0000000000000670

107. Reynolds HR, Maehara A, Kwong RY, Sedlak T, Saw J, Smilowitz NR, et al. Coronary optical coherence tomography and cardiac magnetic resonance imaging to determine underlying causes of myocardial infarction with nonobstructive coronary arteries in women. Circulation. (2021) 143:62440. doi: 10.1161/CIRCULATIONAHA.121.055516

108. Reynolds HR, Picard MH, Spertus JA, Peteiro J. Natural history of patients with ischemia and no obstructive coronary artery disease: the CIAO-ISCHEMIA study. Circulation. (2021) 144:1008-23. doi: 10.1161/CIRCULATIONAHA.120.046791

109. Bairey Merz CN, Handberg EM, Shufelt CL, Mehta PK, Minissian MB, Wei J, et al. A randomized, placebo-controlled trial of late Na current inhibition (ranolazine) in coronary microvascular dysfunction (CMD): impact on angina and myocardial perfusion reserve. Eur Heart J. (2016) 37:150413. doi: 10.1093/eurheartj/ehv647

110. Ford TJ, Stanley B, Sidik N, Good R, Rocchiccioli P, McEntegart M, et al. 1-Year Outcomes of angina management guided by invasive Coronary Function Testing (CorMicA). JACC Cardiovasc Interv. (2020) 13:3345. doi: $10.1016 /$ j.jcin.2019.11.001

111. Crea F, Bairey Merz CN, Beltrame JF, Berry C, Camici PG, Kaski JC, et al. Mechanisms and diagnostic evaluation of persistent or recurrent angina following percutaneous coronary revascularization. Eur Heart J. (2019) 40:2455-62. doi: 10.1093/eurheartj/ehy857

112. Taqueti VR, Di Carli MF. Coronary microvascular disease pathogenic mechanisms and therapeutic options: JACC state-of-the-art review. J Am Coll Cardiol. (2018) 72:2625-41. doi: 10.1016/j.jacc.2018.09.042

113. Shimokawa H, Suda A, Takahashi J, Berry C, Camici PG, Crea F, et al. Clinical characteristics and prognosis of patients with microvascular angina: an international and prospective cohort study by the Coronary Vasomotor Disorders International Study (COVADIS) Group. Eur Heart J. (2021) ehab282. doi: 10.1093/eurheartj/ehab282

114. Jones E, Delia Johnson B, Shaw LJ, Bakir M, Wei J, Mehta PK, et al. Not typical angina and mortality in women with obstructive coronary artery disease: results from the Women's Ischemic Syndrome Evaluation study (WISE). Int J Cardiol Heart Vasc. (2020) 27:100502. doi: 10.1016/j.ijcha.2020.100502 
115. Greenwood BN, Carnahan S, Huang L. Patient-physician gender concordance and increased mortality among female heart attack patients. Proc Natl Acad Sci USA. (2018) 115:8569-74. doi: 10.1073/pnas.18000 97115

116. Mochari-Greenberger H, Mills T, Simpson SL, Mosca L. Knowledge, preventive action, and barriers to cardiovascular disease prevention by race and ethnicity in women: an American Heart Association national survey. $J$ Womens Health (Larchmt). (2010) 19:1243-9. doi: 10.1089/jwh.2009.1749

117. Bairey Merz CN, Andersen H, Sprague E, Burns A, Keida M, Walsh MN, et al. Knowledge, attitudes, and beliefs regarding cardiovascular disease in women: the women's heart alliance. J Am Coll Cardiol. (2017) 70:12332. doi: 10.1016/j.jacc.2017.05.024

118. Mehta LS, Beckie TM, DeVon HA, Grines CL, Krumholz HM, Johnson $\mathrm{MN}$, et al. Acute myocardial infarction in women: a scientific statement from the American Heart Association. Circulation. (2016) 133:91647. doi: 10.1161/CIR.0000000000000351

119. Peters SAE, Muntner P, Woodward M. Sex differences in the prevalence of, and trends in, cardiovascular risk factors, treatment, and control in the United States, 2001 to 2016. Circulation. (2019) 139:102535. doi: 10.1161/CIRCULATIONAHA.118.035550
Conflict of Interest: CB: Sanofi, Abbott Diagnostics, and iRhythm. JW: Abbott Vascular.

The remaining authors declare that the research was conducted in the absence of any commercial or financial relationships that could be construed as a potential conflict of interest.

Publisher's Note: All claims expressed in this article are solely those of the authors and do not necessarily represent those of their affiliated organizations, or those of the publisher, the editors and the reviewers. Any product that may be evaluated in this article, or claim that may be made by its manufacturer, is not guaranteed or endorsed by the publisher.

Copyright (C) 2021 Mehta, Wei, Shufelt, Quesada, Shaw and Bairey Merz. This is an open-access article distributed under the terms of the Creative Commons Attribution License (CC BY). The use, distribution or reproduction in other forums is permitted, provided the original author(s) and the copyright owner(s) are credited and that the original publication in this journal is cited, in accordance with accepted academic practice. No use, distribution or reproduction is permitted which does not comply with these terms. 